$\mathrm{BFJ}$

123,13

88

Received 7 October 2020

Revised 21 January 2021

Accepted 17 February 2021

\section{Consumer appreciation of a shark-free eco-label for small pelagics}

\author{
Luca Mulazzani ${ }^{\circledR}$ \\ Department of Agricultural and Food Sciences, \\ Alma Mater Studiorum - Università di Bologna, Bologna, Italy \\ Laura Piredda \\ Alma Mater Studiorum - Università di Bologna, Bologna, Italy \\ Marija Cerjak \\ Department of Marketing in Agriculture, Faculty of Agriculture, University of Zagreb, \\ Zagreb, Croatia, and \\ Luca Camanzi \\ Department of Agricultural and Food Sciences, \\ Alma Mater Studiorum - Università di Bologna, Bologna, Italy
}

\begin{abstract}
Purpose - The objective of this study is to assess if Italian fish consumers are sensible to shark protection and if they would contribute paying more for small pelagic fishes coming from fisheries that are certified as "shark-free".

Design/methodology/approach - Contingent valuation is used to estimate willingness to pay with a double approach, including a dichotomous choice and an open-ended question. Inconsistency between the two answers is allowed. This allows the correction of two sources of bias (i.e. preference uncertainty and anchoring effect) and has permitted that the two estimation methods converged to the same result.

Findings - Consumers show interest for the "shark-free" label. Premium price is estimated at $+26 \%$. Variables affecting willingness to pay (WTP) in the sample are age, income, environmental attitude, knowledge of organic labels and frequency of small pelagics' consumption. Results need to be confirmed by a replication on a larger (probabilistic) sample and with a different distribution of bids.

Originality/value - Ecosystems provide different benefits to humankind, including non-use services, such as the satisfaction to know that a species is well conserved. Generally, appreciation is higher for what are considered charismatic species. In this paper, the authors investigate if sharks can be considered charismatic species despite their "bad reputation". The interest in shark survival is measured indirectly using a "shark-free" label on a commercial species like anchovy, allowing to increase the value added of this low-price species.

Keywords Eco-label, Willingness to pay, Contingent valuation, Premium price, Sustainable fisheries Paper type Research paper
\end{abstract}

(C) Luca Mulazzani, Laura Piredda, Marija Cerjak and Luca Camanzi. Published by Emerald Publishing Limited. This article is published under the Creative Commons Attribution (CC BY 4.0) licence. Anyone may reproduce, distribute, translate and create derivative works of this article (for both commercial and non-commercial purposes), subject to full attribution to the original publication and authors. The full terms of this licence may be seen at http://creativecommons.org/licences/by/4.0/legalcode

Funding: This study has been realized in the framework of the project PRIZEFISH "Piloting of eco-innovative fishery supply-chains to market added-value Adriatic fish products" funded by the Call 2014-2020 Interreg V-A Italy-Croatia CBC Programme - Priority Axis: Blue innovation. Subsisdy Contract $\mathrm{N}^{\circ} 10043583$

We are grateful to our project partners for the collaboration they apported with comments and suggestions. In particular, the proposal for a "shark-free" label is born from an idea of the Experimental Center for Habitat Conservation (CESTHA) that is currently working to develop the certification guidelines. 


\section{Introduction}

Ecosystems provide different benefits, both consumptive and non-consumptive, that humankind enjoys. They can also provide non-use services, such as the satisfaction to know that a species (or a habitat) is well-conserved and can continue to survive on Earth (i.e. existence value). In this perspective, the existence of animal species is a public good since their appreciation by people is both non-excludable and non-rivalrous. Generally, appreciation is higher for what are considered charismatic species (Kontoleon and Swanson, 2003), and many campaigns have been specifically developed for the protection of whales, dolphins and turtles. In this paper, we investigate if sharks can be considered charismatic species, if they deserve special attention from citizens and consumers as species that should be protected, and if eco-labelling may represent a tool to pursue this objective.

The fact that the existence of sharks may be considered as a public good is not trivial. Many people around the world know them for their "bad reputation". The movie Jaws, directed by Steven Spielberg in 1975, developed among people a great fear of sharks. Mass media also allowed the dissemination of information regarding shark attacks, thus influencing public attitudes (Mazzoldi et al., 2019). On the other hand, it is now well-known the role of sharks as key species in marine ecosystems and the critical effects their reduction would cause directly to the trophic chain (Ferretti et al., 2008; Clua et al., 2011). The disappearance of multiple species leads to a domino collapse of all the benefits humans can gain from the habitat.

Sharks are exploited all over the world, both as target species (for their fins, liver, cartilage and meat) and as secondary catch of fisheries interested in other valuable species. In the Adriatic Sea, one of the main target resources is small pelagic fish, including anchovies (Engraulis encrasicolus) and sardines (Sardina philcardus), which represent $41 \%$ of total Adriatic catches (Mipaaf and NISEA, 2018). However, pelagic trawlers do not only catch target species but also different elasmobranchs, like sharks and rays, which end up caught in the nets. These can be considered as accidental catches, even if, when occur, they are normally sold on the market.

As pointed out by the well-known "tragedy of the commons" (Hardin, 1968), market alone is not able to provide incentives for a rational management of common resources. The situation is even worse for by-catch of non-commercial and non-target species (such as dolphins or turtles and sharks), where catches are accidental and driven neither by consumers nor by fishers' deliberate behaviors. Nevertheless, the survival of endangered and charismatic species has a value for people, as shown by the empirical literature (Loomis and White, 1996). Thus, it is necessary to find tools that can both inform consumers and provide the possibility for citizens to affect the choices of fishers.

As a response to the rising sustainability concerns related to fish stocks and the impacts of fisheries on marine habitats, several eco-labelling certifications have been developed over the last decades (Kirby et al., 2014). Indeed, there is abundant evidence that consumers generally express a willingness to pay a premium to "protect the environment", which responds to moral motivations (Salladarré et al., 2010) and is a form of altruism or a contribution to some public good (Mason, 2012) such as ecosystems health or biodiversity. However, despite worldwide growth in fisheries eco-labelling schemes, Italian consumers and retailers have only very recently shown an interest in such certifications.

In front of a high diffusion of new eco-certification schemes, their effective impact is still unclear (Thøgersen et al., 2010). The present study assesses stated consumer appreciation for a novel "shark-free" eco-label proposed to enhance sustainability and value generation for small pelagic species caught in the Northern Adriatic Sea. "Shark-free" would entail that sharks are neither caught nor damaged during fishing activities. A contingent valuation approach is used to estimate the willingness to pay (WTP) of Italian consumers for certified products compared with traditional products. The analysis of consumers' WTP for this label
Appreciation of a shark-free label 
BFJ

123,13

permits to evaluate their interest in shark survival. At the same time, this analysis on a commercial species (i.e. anchovy), the fishery of which can cause shark by-catch, would evaluate the potential to introduce this label to the market and to protect shark populations by setting incentives to fishers. In the next section, we will focus on the background and the literature related to the adoption of eco-labels to provide value to non-use ecosystem services. Then, we will present the methodology used to evaluate the hypothetical inclusion of this nonuse value (related to shark protection) in the price of anchovies. Finally, we will present and discuss the main findings.

\section{Theoretical background}

Sharks are included in the so-called K-selected species, which means that they reach sexual maturity very late, have low reproductive rates, long gestation and produce few offspring. Their sensitive biological characteristics limit the ability of these species to recover from heavy fishing pressure (Gallagher and Hammerschlag, 2011; Bargione et al., 2019). Spiny dogfish (Squalus acanthias) is one of the most valuable commercial sharks and is globally listed as vulnerable by the IUCN classification and as endangered in the Mediterranean Sea (Bargione et al., 2019). Common smooth-hound (Mustelus mustelus) is classified as vulnerable in the Mediterranean Sea (Farrell and Dulvy, 2016). The Northern Adriatic has faced a great decrease of shark populations and, unfortunately, there is still a lack of information about bycatch data regarding sharks (Bonanomi et al., 2018).

Sharks can be valuable to human population in different ways; in other words, they provide different ecosystem services (ESs). According to the Millennium Ecosystem Assessment, ESs are classified into four categories: supporting, provisioning, regulating and cultural. It is also important to distinguish between final (if they are directly enjoyed by people) or intermediate (if they are necessary for the production of other ESs) ESs (Boyd and Banzhaf, 2007). The System of Environmental-Economic Accounting of the United Nations defines final ESs as the contributions of ecosystems to benefits used in economic and other human activities (United Nations et al., 2014). For example, shark meat is clearly a final ES entering into the group of provisioning services. The role that sharks have on the trophic chain is, on the other hand, an intermediate supporting ES. Sharks can also provide cultural services: in some regions of the world, people travel to go cage diving with great white sharks. As stated by Clua et al. (2011): "When a live shark is involved in ecotourism, it has a higher value than a shark that is caught".

In some cases, the use value of sharks, for example when diving is involved, can be measured as a fraction of the value added generated by specific economic activities. In other cases, benefits for people are not embedded into economic activities, and other techniques are needed to estimate their non-marketable contribution to human wealth. The same can be said for non-use value, as it is the case of the existence value (Loomis and White, 1996).

Eco-labelling is a tool that permits markets, through consumption preferences, to internalize some of the values of ESs (in particular non-use values) in the price of sustainable fish products. In this way, consumers may affect fishers' choices (Farmery et al., 2017). The main aim of eco-labels is in fact to inform consumers about environmental and ecological issues, providing them with information regarding production methods and the effect they have on the ecosystem and giving people the chance to evaluate their purchase choices (Gardiner and Viswanathan, 2004).

Nowadays there are a myriad of eco-certifications available for many products (Song et al., 2019). Thus, educating consumers to choose eco-friendly products is challenging, and the actual success of eco-labels in advising consumers is still unclear (Thøgersen et al., 2010). However, thanks to this interest, many fisheries have improved their fishing methods, 
becoming more sustainable and responsible. Marine Stewardship Council (MSC), Dolphin safe and Friends of the Sea are some of the most known third-party eco-labels used in fish products (Gopal and Boopendranath, 2013).

Since many shark species are considered endangered in some areas, eco-labelling would permit to internalize the existence value of sharks into the price of commercial species, if consumers are interested in their preservation. Minimization of shark by catch is already included in some existing eco-label schemes (e.g. MSC) (Kirby et al., 2014), but none of these consider elasmobranchs conservation as the only objective of their certification. On the contrary a "shark-free" label, applied to anchovies, would be comparable with the "Dolphin Safe Tuna" label that was developed in the nineties and is still used (Gardiner and Viswanathan, 2004; Gopal and Boopendranath, 2013; Kirby et al., 2014; Miller and Bush, 2015).

In spite of the growing interest for eco-labels in fisheries, yet there is a lack of sufficient literature quantifying the level of price premiums for these products (Roheim et al., 2011). Roheim et al. (2011) use a hedonic analysis to measure that MSC-certified frozen processed Alaska pollock products in the London metropolitan area have a statistically significant premium of $14.2 \%$. The same approach has been adopted by Asche and Bronnmann (2017), verifying that "MSC premiums in Germany vary substantially between species, from a hefty $30.6 \%$ for the high-end species cod, to a $4 \%$ premium for Alaska pollock, and no premiums for saithe." In the same paper, the authors review previous studies, indicating an average premium of $3 \%$ using German scanner data for 11 species and a premium of $10.1 \%$ for haddock using store observation data in Glasgow. Martinez-de-Ibarreta and Valor (2017) focus on the Spanish market to verify that MSC-labelled products do not systematically sell at a premium.

\section{Data and methods}

\subsection{Data}

For this study, two hundred face-to-face interviews were done to consumers of EmiliaRomagna region, in the period September-November 2019. The survey was composed by eighteen questions. Since the sample is small, locally concentrated in a single region of Italy and non-probabilistic [1], several exact replications (Tsang and Kwan, 1999; Hunter, 2001; Ward and Kemp, 2019) have been conducted to allow theoretical generalization based on common sense (e.g. logical inference), rather than on statistical inference (Coleman, 2019).

The literature on labelled products (Garavaglia and Mariani, 2017; Sanjuan-Lopez and Resano-Ezcaray, 2020) indicates that the place of residence (e.g. population with deeper roots in the territory of production) may affect the WTP. For this reason, the survey was carried out in one large coastal town (Ravenna) and in one small inland town (Pavullo nel Frignano) inside four shops. The interviews have been equally distributed in one fish shop and one supermarket in each city. After removal of four invalid responses, we obtained 196 valid respondents. In other words, replications include two geographical places and two retailer typologies. WTP will be tested independently for every couple of replication in order to see if results are consistent under different conditions (Coleman, 2019; Killeen, 2019; National Academies of Sciences Engineering and Medicine, 2019).

\subsection{Willingness to pay}

This study investigates consumer orientation towards shark eco-labelling based on a Contingent Valuation approach, which permits to reveal individual preferences for products that are not on the market yet (Hanemann, 1984; Loomis, 1988). Traditionally, contingent valuation has been used for the valuation of public goods, but in recent years it has been 
$\mathrm{BFJ}$

123,13

applied to private goods, including products with specific ecological attributes such as organic products (Díaz et al., 2012; Owusu and Owusu, 2013; Nandi et al., 2017), quality labels (Ulloa and Gil, 2008), sustainability claims (Zander and Feucht, 2018) and country of origin (Klöckner et al., 2013).

The objective is to determine people's WTP for a "shark-free" certified product compared to the ordinary small pelagic fish product. In other words, WTP represents the difference between consumers' surplus before and after adding the "shark free" label. Consumers were asked to answer how much they would be prone to pay for "shark-free" eco-labelled anchovies through a two steps approach widely used for contingent valuation (Santagata and Signorello, 2000), firstly using a close-ended question and later an openended question.

With the first procedure, a single dichotomous choice is done $\left(\mathrm{WTP}_{\mathrm{dc}}\right)$ by the respondent (i.e. single bound dichotomous choice), between accepting or not to pay a given price (which is different from consumer to consumer) for "shark-free" anchovies, having as a reference the average price of conventional anchovies, which in the period of the analysis was $6 € / \mathrm{kg}$. In order to select the bid amounts to be proposed to consumers, we used as a benchmark, the premium prices emerged in previous studies for different fish products (Asche and Bronnmann, 2017). The literature on optimal bid design suggests to avoid extreme bids since bids in the tails of the distribution could bias the results (Kanninen, 1995). Finally, the following values have been chosen [6.3, 6.6, 6.9, 7.2, 7.5], uniformly assigned to the respondents of both towns (and shops), where the maximum bid ( $7.5 € / \mathrm{kg}$ ) corresponds to a $25 \%$ premium price compared with conventional anchovies. Data are analyzed using the Hanemann approach (Hanemann, 1984) to estimate the mean maximum willingness to pay. A dichotomous choice logit model for which the price and the constant, which are the only attributes, is used. The mean $\mathrm{WTP}_{\mathrm{dc}}$ is determined using the expression:

$$
\mathrm{WTP}_{\mathrm{dc}}=-\alpha / \beta
$$

where $\alpha$ is the constant term and $\beta$ is the coefficient of the explanatory variable for the proposed bid.

With the second procedure, the maximum willingness to pay for the product is asked with an open-ended question, without any hint or advice, and the mean $\mathrm{WTP}_{\mathrm{oe}}$ is simply calculated as the average of the answers.

\subsection{Biases and correction procedure}

This two-steps approach has several advantages since it permits to generate two classes of data (discrete and continuous variables), provides more statistical information and allows comparison of WTP values obtained from the discrete choice with those obtained from the open-ended question.

However, every approach to contingent valuation present biases, leading to differences between actual behavior and measured attitudes (Bishop and Heberlein, 1979). The dichotomous choice format is probably more familiar and requires less cognitive effort since it allow respondents to behave as when they are shopping at the market, simply saying yes or not to a posted price [2] (Brown et al., 1996), but the decision may be affected by the desire of the respondent to satisfy the expectations of the interviewers (Henrich et al., 2005), by moral concerns or by the coexistence of more objectives in responding. For example, "yes" answers may simply indicate whether people view the good at issue favorably, expressing an opinion on shark conservation, rather than on their actual WTP (Brown et al., 1996). Another cause of bias in discrete choice, known as preference uncertainty, is that respondents who are willing to pay 
something but do not have a precise estimate of their WTP (or only have an initial range of plausible WTPs) may respond "yes" to any reasonable suggestion. In contrast, when asked an open-ended question, the respondent is given no cue and is forced to either estimate WTP or refuse to answer (Brown et al., 1996).

Independent studies based on discrete choice and on open-ended questions indicate that $\mathrm{WTP}_{\mathrm{dc}}$ results higher than $\mathrm{WTP}_{\mathrm{oe}}$ (Brown et al., 1996). By contrast, if both approaches are realized together, as in this study, the open-ended bid may result affected by an anchoring effect, determined by the initial answer.

In this study, differently from other researches (Santagata and Signorello, 2000), respondents were not solicited to give maximum WTP answers consistent with the choice made in the previous dichotomous discrete choice. This approach has been chosen to verify if an initial bias in the discrete choice (i.e. preference uncertainty) can be later corrected (allowing inconsistency) by an open-ended question. At the same time, this approach permits to verify if the anchoring effect on open-ended questions can be decreased allowing inconsistency.

As expected, in our survey we found that there is a sensible percentage of population that is not coherent when must indicate its maximum WTP (i.e. $\mathrm{WTP}_{\mathrm{oe}}$ ). In other words, there are 24 persons ( $12 \%$ of the sample) that have previously accepted a given bid and immediately later, when asked their maximum WTP for "shark-free" anchovies, indicated a price that was lower than the already accepted bid. We will refer to this group of people as "incoherents with preference uncertainty" (or simply incoherents) because we suppose that this group suffered of preference uncertainty, or other similar yes-biased effect (Brown et al., 1996), when they had to decide to accept or not the proposed bid. However, it is likely that these persons were able, when they had to provide an open-ended answer ( $\left.\mathrm{WTP}_{\mathrm{oe}}\right)$, to reformulate the problem and correct their previous choice.

This large percentage of "incoherents" made us think to the possibility to correct the answers affected by "preference uncertainty" (Table 1). Thus, we have prepared a different dependent variable (Accept_corrected) where the value for incoherent respondents has been changed from "yes" to "no". $\mathrm{WTP}_{\mathrm{dc}}$ is then calculated using both original data $\left(\mathrm{WTP}_{\text {odc }}\right)$ and "corrected" data $\left(\mathrm{WTP}_{\mathrm{cdc}}\right)$ to verify if this can cause significant changes in the results of the logit model.

\subsection{Valuation function}

After WTP, it is common in the literature to estimate a valuation function (Johnston et al., 2001), i.e. a function that relates discrete choice (logit model) and maximum WTP to variables that are supposed to have an influence on them. A binomial logit model and an ordinary least squares (OLS) model are used, respectively. The description and name of the variables used to estimate the models are presented in Table 2.

Variables are chosen taking into consideration the existing literature on the use of stated preferences on eco-labels (Johnston et al., 2001; Jaffry et al., 2004; Brécard et al., 2009; Salladarré et al., 2010). They include:

\begin{tabular}{lcc} 
Bid amount & Acceptance rate with original data \% & Acceptance rate with "corrected" data \\
\hline 6.3 & 95 & 95 \\
6.6 & 98 & 93 \\
6.9 & 88 & 85 \\
7.2 & 98 & 63 \\
7.5 & 75 & 58
\end{tabular}

Appreciation of a shark-free label 
$\mathrm{BFJ}$ 123,13

Acronym
Dependent variables
Accept

MAX_WTP

94
If the respondent is willing to accept sharkfree anchovy price ${ }^{1}$

Maximum Willingness to Pay

Bid amount offered in dichotomous choice

Town of the survey

Shop

Kind of shop

Information

If question on awareness of shark decline has been asked before or after WTP

Independent variables

Fish_consump Frequency of fish consumption

Pelagic_consump Frequency of small pelagic consumption

Table 2.

List of variables and values obtained from the survey
Shark_consump

Know_PDO

Know_Org

Know_MSC

Origin

Adriatic

Method

Freshness

Calories

Easy_preparatin

PriceX

Certified

Habit

Shark_Decline

Shark_Interest

Recycle

Env_Good

Less_Impact

House_Products

Frequency of shark consumption

If the respondent recognizes the PDO label

If the respondent recognizes the Organic label

If the respondent recognizes the MSC label

If the origin is among top four attributes ${ }^{3}$

If the Adriatic origin is among top four attributes $^{3}$

If the method of production is among top four attributes $^{3}$

If the freshness is among top four attributes ${ }^{3}$

If the calories content is among top four attributes $^{3}$

If the ease of preparation is among top four attributes $^{3}$

If the price is among top four attributes ${ }^{3}$

If the eco-certification is among top four attributes $^{3}$

If the habit is among top four attributes ${ }^{3}$

If the respondent knows that shark are

declining

If the respondent thinks that people can be interested in "shark-free"

"Whenever possible, I buy products packaged in reusable or recyclable containers" (EMCB1) $^{4}$ products when there is a cheaper alternative" $\left(\right.$ EMCB2) ${ }^{4}$

"When there is a choice, I always choose the product that contributes to the least amount of environmental damage" (EMCB3) ${ }^{4}$

the environment" (EMCB4) ${ }^{4}$

Gender
"I have paid more for environmentally friendly
Categories

Result from the survey

If yes $=1,0$ otherwise

1: 177

Open-Ended question

Mean: 7.6

$€ / \mathrm{kg}$

$[6.3,6.6,6.9,7.2,7.5]$

Ravenna $=0$,

Pavullo $=1$

Fishmonger $=0$,

Supermarket 1

Before $=0$, After $=1$

0-4 scale ${ }^{2}$

0-4 scale $^{2}$

0-4 scale ${ }^{2}$

If yes $=1,0$ otherwise

If yes $=1,0$ otherwise

If yes $=1,0$ otherwise

If yes $=1,0$ otherwise

If yes $=1,0$ otherwise

If yes $=1,0$ otherwise

If yes $=1,0$ otherwise

If yes $=1,0$ otherwise

If yes $=1,0$ otherwise

If yes $=1,0$ otherwise

If yes $=1,0$ otherwise

Mean: 3.1

Mean: 2.2

Mean: 0.5

1: 77

1: 100

1: 70

1: 144

1: 46

1: 87

1: 157

1: 28

1: 53

1: 38

1: 10

If yes $=1,0$ otherwise

If yes $=1,0$ otherwise

1: 35

1: 105

If yes $=1,0$ otherwise

1: 141

1-5 Likert Scale

Mean: 3.6

1-5 Likert Scale

Mean: 3.6

1-5 Likert Scale

Mean: 3.8

1-5 Likert Scale

Mean: 3.3

Male $=0$, Female $=1$

1: 131 


\begin{tabular}{|c|c|c|c|}
\hline Acronym & Variable & Categories & $\begin{array}{l}\text { Result from } \\
\text { the survey }\end{array}$ \\
\hline Age & Age & $\begin{array}{l}0-4 \text { scale, where } \\
0=\text { does not answer }\end{array}$ & \\
\hline School_title & School title & $\begin{array}{l}0-3 \text { scale, where } \\
0=\text { does not answer }\end{array}$ & \\
\hline $\begin{array}{l}\text { Family } \\
\text { Income }\end{array}$ & $\begin{array}{l}\text { Number of components of the family } \\
\text { Family income }\end{array}$ & $\begin{array}{l}\text { Open-Ended question } \\
0-4 \text { scale, where } \\
0=\text { does not answer }\end{array}$ & \\
\hline
\end{tabular}

$0-3$ scale, where

$0=$ does not answer

Open-Ended question

$0-4$ scale, where

0 does not answer

(1) Consumer's socio-economic characteristics: sex, age, education and income.

(2) Consumption habits: frequency of consumption (for different species or group of species) and aspects considered in the choice of fish [3] (origin, method of production, freshness, nutritional properties, preparation, price, habit and ecolabels).

(3) Knowledge of quality labels and eco-labels: EU Protected Designation of Origin (PDO), Organic and MSC.

The literature on labelled products (e.g. PDO and Organic products) has begun to include several aptitudes of consumers (such as the interest in environmental issues) in order to explain the preference of different groups of stakeholders (Yangui et al., 2019). For this reason, we have included an index of the propensity to environmental behavior, measured trough a set of four questions taken from the ethically minded consumer behaviour (EMCB) scale (Sudbury-Riley and Kohlbacher, 2016). The EMCB scale has been recently used to evaluate several choices of consumers including retail shops (Sánchez-González et al., 2020), brands (Rasool et al., 2020) and product's attributes (Capitello and Sirieix, 2019).

Since information generally plays an essential role in the appreciation of eco-labelling (Salladarré et al., 2010), we asked if respondents knew that sharks' stocks were declining due to fishing activity, and we split the sample in two subsamples, one where this question was asked before of dichotomous discrete choice and maximum WTP, and one when this was asked after. This treatment can be considered as a further replication of the survey, in this case a "conceptual replication" (Tsang and Kwan, 1999; Hunter, 2001; Ward and Kemp, 2019) and will be used to verify if WTP is consistent under different conditions.

We finally included a more general question "Do you think people would be interested in this kind (i.e. "shark-free") of certification?" to catch other possible variables not explicitly considered in the model.

Not all the variables are included into the final model since several steps for variable selection are followed. First, statistical significance is tested separately for groups of variables (e.g. socio-economic characteristics, consumption habits, knowledge of quality labels and eco-labels and EMCB questions) for both the logit model (i.e. discrete choice) and the OLS model (open-ended question). Later, only the variables with statistically significant effects in either the logit model or the OLS model are selected for the final models. 
BFJ

123,13

\section{6}

\section{Results}

In Table 2, the main characteristics of the sample are illustrated. The sample is mainly represented by women and is well represented as age, education and wealth. The main ranges of age are $50-65(37 \%)$, followed by $35-49(27 \%)$ and $>65(22 \%)$. The main ranges of monthly family income are $1,500-3,000 €(40 \%)$ and $3,000-4,500 €(19 \%) ; 23 \%$ of the respondents did not want to answer this question.

Fish is purchased by $39 \%$ of the sample "twice or more times a week" and by $37 \%$ "once a week". The majority of respondents $(27 \%)$ buy pelagic fish "once a week", while most of the people $(70 \%)$ never buy sharks. The main attributes that are considered for the choice of the fish are freshness $(78 \%$ ) and origin (i.e. landing nation, $72 \%$ ). Less important are the method of production ( $43 \%)$ and the other attributes, including price $(19 \%)$ and the presence of ecolabels or certifications (5\%) that is, among all, the less important attribute.

Only few respondents state to recognize the most common quality labels and eco-labels shown to them: exactly $50 \%$ affirm to have seen the organic label applied to some food and percentage decrease to $38 \%$ and $35 \%$ in the case of PDO and MSC labels. However, when asked to explain the meaning of the labels, percentage decreases sensibly, and only $17 \%$ of people (for each label) is able to provide an appropriate description.

People who state to know that sharks are in decline as an effect of fisheries represent $52 \%$ of the sample. There is not statistically significant difference in the percentage considering respondents that had to answer to this question before or after expressing their WTP. Respondents who think that consumers would be interested in a "shark-free" certification represent $70 \%$ of the sample. Finally, statements taken from the EMCB scale, where consumers' propensity to environmental behavior, are measured using a Likert scale from 1 to 5 , present average values from 3.3 to 3.8 .

As explained in the methodology section, WTP was firstly estimated pairwise for all the replications adopted in the survey (i.e. Ravenna vs Pavullo, supermarket vs fishmonger and information vs no information), in order to see if results are consistent under different conditions (Coleman, 2019; Killeen, 2019; National Academies of Sciences Engineering and Medicine, 2019). Finally, it was estimated for the entire sample (Table 3).

$\mathrm{WTP}_{\text {odc }}$ was estimated, for the entire sample, at $8.35 € / \mathrm{kg}$ (representing $a+39 \%$ premium price compared to standard anchovy). Results show moderate variability comparing the different replications ( $\mathrm{WTP}_{\text {odc }}$ ranging from 7.84 to 9.36); furthermore, the parameters estimated are not always statistically significant, or they are at levels higher than $1 \%$.

$\mathrm{WTP}_{\mathrm{cdc}}$ was estimated, for the entire sample, at $7.55 € / \mathrm{kg}(+26 \%)$. $\mathrm{WTP}_{\mathrm{cdc}}$ values are very similar through replications (from 7.51 to 7.58), and parameters are all statistically significant at $1 \%$ level.

\begin{tabular}{|c|c|c|c|c|c|c|c|}
\hline \multirow[b]{2}{*}{ Repetition } & \multicolumn{3}{|c|}{ Logit original } & \multicolumn{3}{|c|}{ Logit corrected } & \multirow{2}{*}{$\begin{array}{l}\text { OLS } \\
\text { WTP }\end{array}$} \\
\hline & Constant & Price & WTP & Constant & Price & WTP & \\
\hline Ravenna & 8.14 & -0.87 & 9.36 & $15.77 * * *$ & $-2.1 * * *$ & 7.51 & 7.41 \\
\hline Pavullo & $26.11 * * *$ & $-3.33^{* *}$ & 7.84 & $22.17 * * *$ & $-2.93 * * * *$ & 7.57 & 7.75 \\
\hline Fishmonger & $11.28^{*}$ & -1.29 & 8.74 & $17.79 * * * *$ & $-2.36^{* * * *}$ & 7.54 & 7.75 \\
\hline Supermarket & $16.97^{* *}$ & $-2.1^{* *}$ & 8.08 & $18.49 * * *$ & $-2.45^{* * * *}$ & 7.55 & 7.41 \\
\hline No shark information ${ }^{1}$ & $15.1^{* *}$ & $-1.84^{* *}$ & 8.21 & $18.81 * * *$ & $-2.5^{* * * *}$ & 7.52 & 7.44 \\
\hline Shark information & $12.97 * *$ & $-1.52^{*}$ & 8.53 & $17.44 * * *$ & $-2.3^{* * *}$ & 7.58 & 7.72 \\
\hline TOTAL SAMPLE & $14.06^{* * * *}$ & $-1.68 * * *$ & 8.37 & $18.12^{* * * *}$ & $-2.4^{* * *}$ & 7.55 & 7.58 \\
\hline
\end{tabular}

Estimation of OLS and Logit parameters and WTP results for different replications
Note(s): * Significance at 10\% level. ** Significance at 5\% level. *** Significance at 1\% level. NB: In all OLS estimations, WTP is significantly different from 6 (baseline) at 1\% level. [1]: In this replication, we asked if respondents knew that sharks' stocks were declining due to fishing activity after WTP elicitation 
Finally, $\mathrm{WTP}_{\mathrm{oe}}$ was estimated at $7.58 € / \mathrm{kg}(+26 \%)$. Such as in the case of $\mathrm{WTP}_{\text {cdc }}$, results are very similar for all the replications, ranging from 7.41 (Ravenna and supermarkets) to 7.75 (Pavullo and fishmongers), and are significant at 1\% statistical level (i.e. WTP is statistically different from the baseline of $6 € / \mathrm{kg}$ ).

From these results, we can note that $\mathrm{WTP}_{\text {odc }}$ (using the original data) is appreciably higher than $\mathrm{WTP}_{\mathrm{oe}}$, as it is often noticed in the literature (Santagata and Signorello, 2000). On the contrary, $\mathrm{WTP}_{\mathrm{cdc}}$ and $\mathrm{WTP}_{\mathrm{oe}}$ are practically equal. We conclude that $\mathrm{WTP}_{\mathrm{cdc}}$ and $\mathrm{WTP}_{\mathrm{oe}}$ are probably more accurate than $\mathrm{WTP}_{\text {odc }}$.

We also tested if WTP is significantly affected by the variables "Town", "Shop" and "Information", using OLS and logit estimations for the entire sample where these variables were singularly included. Results indicate that none of these variables are statistically significant in the logit model, using both the original and the "corrected" dataset. On the contrary, "Town" and "Shop" (but not "Information") result to be significant in the OLS model. Thus, the effect of different replications among towns and shops cannot be completely excluded.

Finally, we estimated the coefficients of the valuation functions (Table 4), which are the functions that relate discrete choice (logit model, using both the original and the "corrected" dataset) and maximum WTP (OLS model), with all the independent variables considered in the questionnaire. Hereafter, we present the results of the final models, where only the variables that showed to have coefficients significantly different from zero in the preliminary tests are included (i.e. estimations tests for groups of variables). For the OLS model, the ratio of explained variance to the total variance of the dependent variable (i.e. $R^{2}$ ) is 0.22 . For the two logit models, the rates of prediction success are 0.92 and 0.83 in the case where we use the original dataset or the corrected dataset Table 5.

\begin{tabular}{lccc}
\hline Variable & Logit original & Logit corrected & OLS \\
\hline Const & $15.006(5.864)^{* *}$ & $18.892(4.442)^{* * * *}$ & $6.847(1.543)^{* * * *}$ \\
Price & $-1.863(0.761)^{* *}$ & $-2.777(0.605)^{* * *}$ & $0.066(0.201)$ \\
Town & $0.131(0.657)$ & $0.508(0.506)$ & $0.208(0.167)$ \\
Shop & $0.278(0.595)$ & $0.699(0.467)$ & $-0.230(0.163)$ \\
Fish_Consump & $-0.552(0.401)$ & $0.018(0.273)$ & $-0.149(0.099)$ \\
Pelagic_Consump & $-0.032(0.231)$ & $0.051(0.185)$ & $0.125(0.070)^{*}$ \\
Know_Org & $1.090(0.661)^{*}$ & $0.283(0.478)$ & $0.441(0.165)^{* * *}$ \\
Shark_Decline & $-0.736(0.631)$ & $-1.599(0.508)^{* * *}$ & $-0.292(0.164)^{*}$ \\
Shark_Interest & $1.249(0.597)^{* *}$ & $1.293(0.484)^{* * *}$ & $0.417(0.17)^{* *}$ \\
Recycle & $0.286(0.241)$ & $0.224(0.195)$ & $-0.103(0.079)$ \\
Env_Good & $0.111(0.291)$ & $0.227(0.247)$ & $0.169(0.082)^{* *}$ \\
Age & $-0.214(0.335)$ & $-0.442(0.259)^{*}$ & $-0.130(0.086)^{*}$ \\
Income & $0.410(0.270)$ & $0.573(0.210) * * *$ & $0.137(0.069)^{*}$ \\
$R^{2}$ & 0.265 & 0.342 & 0.220 \\
Log-likelihood & -45.833 & -67.822 & \\
Percentage correctly predicted & $92 \%$ & $83 \%$ & \\
Note(s):I I & & &
\end{tabular}

Note(s): In brackets the standard error. *Significance at $10 \%$ level. **Significance at $5 \%$ level. ***Significance at $1 \%$ level. For OLS, the Breusch-Pagan indicate presence of Heteroscedasticity, thus robust standard errors are used

Appreciation of a shark-free label

\section{.}


$\mathrm{BFJ}$ 123,13

Among the replications used to segment the sample (Town, Shop, and Information), town and shop showed a potential effect for OLS, but this was not confirmed in the final models.

Many other variables have been excluded since they were clearly not related with the dependent variables in the preliminary tests. In particular, none of the variables related with consumer's attitudes (i.e. the stated top four attributes of interest when buying fish) has shown to explain our target variables. Similarly, only one of the variables linked to label knowledge (Know_Org) and two of the variables from the EMCB scale (Recycle and Env_Good) have been included. Gender and education did not show any sign of relevance, while age and income did.

Finally, only few variables result to have a significant effect on the acceptance of the bid and on the stated maximum WTP. The bid amount offered has a clear effect on acceptance (using both the original and the corrected dataset), while it has no effects on maximum WTP. This is an interesting result since it indicates that there are not severe signs of anchoring effects determined by bid offers on Maximum WTP.

Frequency of fish consumption resulted to be relevant for maximum WTP in the preliminary tests, but this was not confirmed in the final models. On the other hand, it is remarkable that maximum WTP be positively associated (at 10\% level) with consumption frequency of small pelagics. This would indicate that people that buy more anchovies (i.e. people that better know and appreciate this species) can be willing to pay more for quality and labelled products.

Knowledge of the organic label is positively related both with maximum WTP and with bid acceptance (using the original dataset). Thus, people that know this label are willing to spend more for "shark-label" anchovies.

Among the EMCB scale statements, only one has a coefficient that is significantly different from zero. Interestingly, this is the item more related with eco-labels since it affirms "I have paid more for environmentally friendly products when there is a cheaper alternative". This variable is positively associated with maximum WTP.

Among the socio-economic variables, income has a coefficient that is significantly different from zero in both the OLS model and in the logit model with the corrected dataset (but not in the logit model with original data); in this latest model, age is also statistically significant. Age has a negative sign, while income has a positive sign.

It is probably a little surprising to note that knowledge that sharks are in decline (as an effect of fisheries) has a negative sign (significantly different from zero for both the OLS model and the logit model with the corrected dataset). Maybe, people who did not know about that, feel guilty, and want to remedy contributing more to save shark.

Finally, as it was expected, part of the variance is explained by the generic statement "I think that people can be interested in shark-free label". One could suspect that this variable may cause multicollinearity in the models affecting the estimation of the other coefficients. However, if this variable is removed from the models, the results (i.e. sign of the coefficients and significance) do not change.

On the other hand, other effects of multicollinearity can be detected for the OLS model due to the high number of variables included. If a Wald test is conducted omitting, from the OLS model shown in Table 4, all the variables that do not look to be statistically significant, the hypothesis that the values of these parameters are zero is rejected at $10 \%$ level, and the adjusted $R^{2}$ value decreases from $17 \%$ to $14 \%$ (i.e. this means that some of the omitted variables had explanatory power). At the same time, among the remaining variables, "Pelagic_Consump" and "Env_Good" cease to be statistically significant (which could be interpreted as a sign of multicollinearity). The same problem is not detected in the logit models [4]. 


\section{Discussion}

The existing literature indicates that the difference between the price paid by consumers for ordinary fish and the price paid for eco-labelled fish ranges between 0 and $+30 \%$, where the highest premium prices are reserved to high-end species (Roheim et al., 2011; Asche and Bronnmann, 2017). Anchovy is normally considered, among Italian fishes, a commodity with very low value (Camanzi et al., 2012), thus, we expected to obtain a low premium price, probably below $15 \%$. On the contrary, we obtained a value included between $+26 \%$ (for the $\mathrm{WTP}_{\mathrm{oe}}$ and $\mathrm{WTP}_{\mathrm{cdc}}$ approaches) and $+39 \%$ (for the $\mathrm{WTP}_{\text {odc }}$ approach).

As well as in all the stated approaches, this result may be overestimated. Brown et al. (1996) consider that overestimation should be lower when the good under consideration is private rather than public. Price premiums linked to eco-labels may hide multifaceted aspects under this perspective. In fact, the good to be purchased is a traditional private good (in this case anchovy), but the attribute to be evaluated is related to a public good (the welfare of sharks).

As the theoretical and empirical literature attests (Brown et al., 1996), dichotomous choice can be easier for respondents (in our research, $12 \%$ of people was not able to indicate a maximum WTP), but can be affected by many more biases, in particular preference uncertainty. In fact, $\mathrm{WTP}_{\text {odc }}$ results to be much higher than $\mathrm{WTP}_{\text {oe }}$. Certainly, this difference would have been lower if we had forced respondents to be coherent when expressing $\mathrm{WTP}_{\mathrm{oe}}$, but we believe that this would have only increased biases through the anchoring effect. Inconsistency (conscious or unconscious, this cannot be known), on the contrary, may permit to avoid the anchoring effect and even to correct the initial preference uncertainty bias. In fact, $\mathrm{WTP}_{\text {cdc }}$ estimated after the correction of the original dataset (in order to take into account the behavior of the "incoherents with preference uncertainty") results to be equal to $\mathrm{WTP}_{\mathrm{oe}}$.

Other biases in our estimation can be linked to the low number of respondents and to nonoptimal bid design. Driven by previous literature results and with the purpose to avoid extreme bids (which could bias the results (Kanninen, 1995)), we have chosen a bid set that resulted to be composed by very low prices, if we consider the high rate of the acceptance and if we consider that $\mathrm{WTP}_{\mathrm{oe}}$ resulted to be higher than the highest bid. Thus, results need to be confirmed by a replication on a larger (probabilistic) sample, and with a different distribution of bids.

Results indicate that people interviewed still have a low knowledge of the most common quality labels and eco-labels, including labels (like PDO and Organic) that are widespread on a large number of Italian food products. From a list of nine attributes that are considered important in order to choose fish products, eco-certification results to be the least important. This should not be surprising since wild-caught fresh fish is normally not certified and only one product from the Italian fisheries (i.e. clams) has obtained the MSC certification in 2019.

People who pay more attention on eco-labels, i.e. people who already know the Organic label and people who affirmed to "have paid more for environmentally friendly products when there is a cheaper alternative" are those who state a higher WTP for the "shark-free" idea. Both Brécard et al. (2009) and Salladarré et al. (2010) attest that best-informed consumers are likely to call for a seafood eco-label.

Results also confirm other findings of the previous literature on fish products. Preferred attributes of choice do not influence consumer' WTP (Johnston et al., 2001). Young (Brécard et al., 2009) and wealthier people (Johnston et al., 2001) look to be more interested in eco-labels. On the contrary, we did not find any significance in the gender variable, while both Johnston et al. (2001) and Brécard et al. (2009) indicated that women were more "green fish consumers".

Typically, the agri-food market is an asymmetric information market where consumers do not have full information (Arfini and Mancini, 2015). In particular, product origin and environmental aspects are credence attributes that consumers cannot evaluate either before or after purchase (Aprile et al., 2012). Thus, certification labels, especially those guaranteed under the framework of the EU quality scheme (e.g. DPO, Organic), are useful strategies which create
Appreciation of a shark-free label 
BFJ

123,13

value by reducing information asymmetry. The literature on food products generally indicates that labels attesting links with the territory or attesting environmental friendly ways of production are well appreciated by Mediterranean people (Aprile et al., 2012; Sanjuan-Lopez and Resano-Ezcaray, 2020). As well as in our study, the literature on organic and PDO labels show that younger individuals and those with higher educational and income levels are those that may will to pay more for these attributes (Aprile et al., 2012). However, several researches confirm our results that consumers can confuse the objectives and the meaning of different certification schemes (Di Pasquale et al., 2016; Yangui et al., 2019) and in many cases, a combination of labels may represent the best option to increase the WTP (Arfini and Mancini, 2015).

\section{Conclusions}

The results of the study indicate that sample consumers, despite the lack of information in eco-labelling, seem to be well disposed toward it. In particular, sharks are not seen with prejudices as it could be expected due to their traditional bad reputation. On the contrary, maybe a label that is clear, easy to understand, tailored on a well-known, iconic species (as it is in the case of "dolphin safe"), can draw attention more than a generic, esoteric acronym that is not able to communicate its objectives (e.g. MSC).

These results should be interpreted in the new framework of the European Green Deal that has the explicit objective (among others) to restore biodiversity. This long-term plan is based on several pillars, including the "Farm to fork" strategy and the "Biodiversity" strategy, both published in May 2020. If the "Farm to fork" strategy stresses the necessity of a legislative proposal for a sustainable food system before of the end of 2023, including a way to harmonize voluntary green claims and to create a sustainable labelling framework, the "Biodiversity" strategy has a specific chapter on fishery products and aims to reduce the adverse impacts of fishing and to eliminate or reduced the by-catch of species in bad conservation status. However, no specific mention is made to an EU label for sustainable fisheries.

In 2016 the European Commission adopted a report on the feasibility of an EU eco-label scheme for fishery products, which concluded that this would represent a high cost option with few net benefits identified, especially because the new eco-label should replace other labels that (in some countries) are now well established (MRAG Consortium, 2016).

In this framework, differently from other food products where EU schemes (e.g. PDO, Organic) demonstrated to be useful to explain the qualities of the product and to add value to it, private labels (such as the one that was proposed in this research) represent the best solution (actually the only solution) for fish products.

Despite these results, the path for the development of the eco-labels for wild-caught fresh seafood is still long. Certified fresh products, normally sold unpackaged, would require investments and reorganization of logistics and supply chains in order to permit the use of ecol-abels. Certified products, in fact, need to be maintained separated from non-certified products all along the chain, from the boat to the supermarket. This adds further costs to that of certification, and the supply chain actors will be ready to this transformation only if they are sure that the benefits are higher than the costs. Finally, it is necessary to verify how the premium price would be transmitted from retailers to fishers, since these must be the first ones to accept to be involved in "shark-free" certification. Sharks are not the target species of pelagic trawlers, but they still are commercial species, they have a price and they contribute to fishers' income. Fishers have the right to take the final decision (Mulazzani et al., 2019), but different classes of consumers (i.e. "sharks' eaters" vs. "sharks' lovers - anchovies' eaters") have the possibility to decide which between the value of sharks' meat (i.e. the provisioning $\mathrm{ES}$ of sharks) and their existence value (i.e. the cultural ES) is higher. Fishers will simply react to this market stimulus. 


\section{ORCID iDs}

Luca Mulazzani Dhttp://orcid.org/0000-0003-2336-9399

Laura Piredda Dhttp://orcid.org/0000-0001-8678-2899

Marija Cerjak Dhttp://orcid.org/0000-0003-0696-4364

Luca Camanzi Dhttp://orcid.org/0000-0003-0738-6279
Appreciation

of a shark-free label

\section{Notes}

1. Consider that for the population size of Emilia Romagna region (about two million of families), a sample size of 200 persons corresponds to a $7 \%$ margin of error (with a $95 \%$ confidence level). At the same time, a sample size of 100 persons corresponds to a $10 \%$ margin of error each for the towns of Ravenna and Pavullo (Daniel, 1999).

2. In our survey, there were 25 persons ( $12 \%$ of the sample) who were not able to indicate a Maximum WTP, confirming that this can be a difficult task. Since all these respondents had previously answered positively to the dichotomous choice, $\mathrm{WTP}_{\text {oe }}$ for them was necessarily fixed equal to the accepted bid.

3. Respondents had to choose four attributes among a list of nine.

4. In both logit models, the omission of the statistically insignificant variables do not alter the significance of the remaining parameters.

\section{References}

Aprile, M.C., Caputo, V. and Nayga, R.M. (2012), "Consumers' valuation of food quality labels: the case of the”, International Journal of Consumer Studies, Vol. 36, pp. 158-165, doi: 10.1111/j.1470-6431. 2011.01092.x.

Arfini, F. and Mancini, M.C. (2015), "The effect of information and co-branding strategies on consumers willingness to pay (WTP) for Protected Desi- gnation of Origin (PDO) products: the case of pre-sliced Parma Ham”, Progress in Nutrition, Vol. 17 No. 1, pp. 15-22.

Asche, F. and Bronnmann, J. (2017), "Price premiums for ecolabelled seafood: MSC certification in Germany", Australian Journal of Agricultural and Resource Economics, Vol. 61 No. 4, pp. 576-589, doi: 10.1111/1467-8489.12217.

Bargione, G., Donato, F., La Mesa, M., Mazzoldi, C., Riginella, E., Vasapollo, C., Virgili, M. and Lucchetti, A. (2019), "Life-history traits of the spiny dogfish Squalus acanthias in the Adriatic Sea”, Scientific Reports, Vol. 9 No. 1, pp. 1-10, doi: 10.1038/s41598-019-50883-w.

Bishop, R.C. and Heberlein, T.A. (1979), "Measuring values of extramarket goods: are indirect measures biased?", American Journal of Agricultural Economics, Vol. 61 No. 5, pp. 926-930.

Bonanomi, S., Pulcinella, J., Fortuna, C.M., Moro, F. and Sala, A. (2018), "Elasmobranch bycatch in the Italian Adriatic pelagic trawl fishery", PloS One, Vol. 13, e0191647.

Boyd, J. and Banzhaf, S. (2007), "What are ecosystem services? The need for standardized environmental accounting units”, Ecological Economics, Vol. 63 Nos 2-3, pp. 616-626, doi: 10. 1016/j.ecolecon.2007.01.002.

Brécard, D., Hlaimi, B., Lucas, S., Perraudeau, Y. and Salladarré, F. (2009), "Determinants of demand for green products: an application to eco-label demand for fish in Europe", Ecological Economics, Elsevier B.V., Vol. 69 No. 1, pp. 115-125, doi: 10.1016/j.ecolecon.2009.07.017.

Brown, T.C., Champ, P.A., Bishop, R.C., Daniel, W., Brown, T.C., Champ, P.A., Bi, R.C. and Mccollum, D.W. (1996), "Which response format reveals the truth about donations to a public good?", Land Economics, Vol. 72 No. 2, pp. 152-166.

Camanzi, L., Mulazzani, L. and Malorgio, G. (2012), "Competitiveness of Italian small pelagics in international trade”, New Medicine, Vol. 11 No. 1, pp. 41-51. 
$\mathrm{BFJ}$ 123,13
Capitello, R. and Sirieix, L. (2019), "Consumers' perceptions of sustainable wine: an exploratory study in France and Italy", Economies, Vol. 7 No. 2, p. 33.

Clua, E., Buray, N., Legendre, P., Mourier, J. and Planes, S. (2011), "Business partner or simple catch? The economic value of the sicklefin lemon shark in French Polynesia", Marine and Freshwater Research, Vol. 62 No. 6, pp. 764-770.

Coleman, R. (2019), Designing Experiments for the Social Sciences, Sage, Thousand Oaks, CA.

Daniel, W. (1999), Biostatistics: A Foundation for Analysis in the Health Sciences, John Wiley and Sons, New York, NY.

Díaz, F.J.M., Martínez, F., Pleite, C., Miguel, J., Paz, M., Gaspar, P., Díaz, F.J.M., Martínez, F., Pleite, C., Miguel, J., Paz, M., Gaspar, P. and GarcI, P.G. (2012), "Consumer knowledge, consumption, and willingness to pay for organic tomatoes", British Food Journal, Vol. 114 No. 3, pp. 318-334, doi: 10.1108/00070701211213447.

Di Pasquale, J., Nannoni, E., Del Duca, I., Adinolfi, F., Capitanio, F., Sardi, L., Vitali, M. and Martelli, G. (2016), "What foods are identified as animal friendly by Italian consumers?", Italian Journal of Animal Science ISSN, Vol. 13 No. 4, p. 3582, doi: 10.4081/ijas.2014.3582.

Farmery, A.K., Watson, R.A., Gardner, C., Jennings, S. and Green, B.S. (2017), "Assessing the inclusion of seafood in the sustainable diet literature", Fish and Fisheries, July 2016, pp. 607-618, doi: 10. 1111/faf.12205.

Farrell, E.D. and Dulvy, N.K. (2016), Mustelus mustelus, The IUCN Red List of Threatened Species 2016, available at: https://www.iucnredlist.org/species/39358/16527988.

Ferretti, F., Myers, R.A., Serena, F. and Lotze, H.K. (2008), "Loss of large predatory sharks from the Mediterranean Sea”, Conservation Biology, Vol. 22 No. 4, pp. 952-964, doi: 10.1111/j.1523-1739. 2008.00938.x.

Gallagher, A.J. and Hammerschlag, N. (2011), "Global shark currency: the distribution frequency and economic value of shark ecotourism”, Current Issues in Tourism, Vol. 14 No. 8, pp. 797-812, doi: 10.1080/13683500.2011.585227.

Garavaglia, C. and Mariani, P. (2017), "How much do consumers value protected designation of origin certifications? Estimates of willingness to pay for PDO dry-cured ham in Italy", Agribusiness, Vol. 33 No. 3, pp. 403-423, doi: 10.1002/agr.

Gardiner, P.R. and Viswanathan, K.K. (2004), Ecolabelling and Fisheries Management, World Fish Center Contribution 174, Penang.

Gopal, T.K.S. and Boopendranath, M.R. (2013), "Seafood ecolabelling”, Fishery Technology, Vol. 50, pp. 1-10, doi: 10.1002/9781444301380.

Hanemann, W. (1984), "Welfare evaluations in contingent valuation experiments with discrete responses", American Journal of Agricultural Economics, Vol. 66 No. 3, pp. 332-41.

Hardin, G. (1968), "The tragedy of the commons", Science, Vol. 162, pp. 1243-1248.

Henrich, J., Boyd, R., Bowles, S., Camerer, C., Fehr, E., Gintis, H., McElreath, R., Alvard, M., Barr, A., Ensminger, J., Henrich, N.S., Hill, K., Gil-White, F., Gurven, M., Marlowe, F.W., Patton, J.Q. and Patton, D. (2005), "Economic man' in cross-cultural perspective: behavioral experiments in 15 small-scale societies", Behavioral and Brain Sciences, Università di Bologna, Sistema Bibliotecario d'Ateneo, Vol. 28 No. 6, pp. 795-815, doi: 10.1017/S0140525X05000142.

Hunter, J.E. (2001), "The desperate need for replications", Journal of Consumer Research, Vol. 28 No. 1, pp. 149-158.

Jaffry, S., Pickering, H., Ghulam, Y., Whitmarsh, D. and Wattage, P. (2004), "Consumer choices for quality and sustainability labelled seafood products in the UK", Food Policy, Vol. 29 No. 3, pp. 215-228, doi: 10.1016/j.foodpol.2004.04.001.

Johnston, R.J., Wessells, C.R., Donath, H. and Asche, F. (2001), "Measuring consumer preferences for ecolabeled seafood: an international comparison", Journal of Agricultural and Resource Economics, Vol. 26 No. 1, pp. 20-39, doi: 10.2307/40987093. 
Kanninen, B.J. (1995), "Bias in discrete response contingent valuation", Journal of Environmental Economics and Management, Vol. 28, pp. 114-125, doi: 10.1006/jeem.1995.1008.

Killeen, P.R. (2019), "Predict, control, and replicate to Understand: how statistics can foster the fundamental goals of science", Perspectives on Behavior Science, Vol. 42, pp. 109-132.

Kirby, D.S., Visser, C. and Hanich, Q. (2014), "Assessment of eco-labelling schemes for Pacific tuna fisheries”, Marine Policy, Elsevier, Vol. 43, pp. 132-142, doi: 10.1016/j.marpol.2013.05.004.

Klöckner, H., Langen, N. and Hartmann, M. (2013), "COO labeling as a tool for pepper differentiation in Germany: insights into the taste perception of organic food shoppers", British Food Journal, Vol. 115 No. 8, pp. 1149-1168, doi: 10.1108/BFJ-07-2011-0175.

Kontoleon, A. and Swanson, T. (2003), "The willingness to pay for property rights for the Giant Panda: can a charismatic species be an instrument for nature conservation?", Land Economics, Vol. 79 No. 4, pp. 483-499, doi: 10.2307/3147295.

Loomis, J.B. (1988), “Contingent Valuation using dichotomous choice models”, Journal of Leisure Research, Vol. 20 No. 1, pp. 45-56.

Loomis, J.B. and White, D.S. (1996), "Economic benefits of rare and endangered species: summary and meta- analysis", Ecological Economics, Vol. 18 No. 3, pp. 197-206, doi: 10.1016/0921-8009(96) 00029-8.

Martinez-de-Ibarreta, C. and Valor, C. (2017), "Is it worth getting labeled? The case of MSC-certified seafood", Journal of International Food and Agribusiness Marketing, Vol. 29 No. 17, pp. 197-215.

Mason, C.F. (2012), "The economics of eco-labeling: theory and empirical implications", International Review of Environmental and Resource Economics, Vol. 6 No. 4, pp. 341-372, doi: 10.1561/101. 00000054.

Mazzoldi, C., Bearzi, G., Brito, C., Carvalho, I., Desiderà, E., Endrizzi, L., Freitas, L., Giacomello, E., Giovos, I., Guidetti, P., Ressureição, A., Tull, M. and MacDiarmid, A. (2019), "From sea monsters to charismatic megafauna: change in perception and use of large marine animals", PloS One, Vol. 14 No. 12, e0226810.

Miller, A.M.M. and Bush, S.R. (2015), "Authority without credibility? Competition and conflict between ecolabels in tuna fisheries”, Journal of Cleaner Production, Elsevier, Vol. 107, pp. 137-145, doi: 10.1016/j.jclepro.2014.02.047.

Mipaaf and NISEA (2018), Programma Nazionale Raccolta Dati Alieutici, Mipaaf.

MRAG Consortium (2016), Feasibility Report on Options for an EU Ecolabel Scheme for Fishery and Aquaculture Products, MRAG, London, available at: https:/ec.europa.eu/fisheries/sites/ fisheries/files/docs/body/feasibility-report-eu-ecolabel-scheme-for-fishery-and-aquacultureproducts_en.pdf.

Mulazzani, L., Camanzi, L. and Malorgio, G. (2019), "Multifunctionality in fisheries and the provision of public goods", Ocean and Coastal Management, Elsevier, Vol. 168, pp. 51-62, October 2018, doi: 10.1016/j.ocecoaman.2018.10.037.

Nandi, R., Bokelmann, W., Gowdru, N.V. and Dias, G. (2017), "Factors influencing consumers' willingness to pay for organic fruits and Vegetables: empirical evidence from a consumer survey in India factors influencing consumers' willingness to pay for organic fruits and vegetables”, Journal of Food Products Marketing, Routledge, Vol. 23 No. 4, pp. 430-451, doi: 10.1080/10454446.2015.1048018.

National Academies of Sciences Engineering and Medicine (2019), Reproducibility and Replicability in Science, The National Academies Press, Washington DC.

Owusu, V. and Owusu, M. (2013), "Consumer willingness to pay a premium for organic fruit and vegetable in Ghana”, International Food and Agribusiness Management Review, Vol. 16 No. 1 , pp. $67-86$.

Rasool, S., Cerchione, R. and Salo, J. (2020), “Assessing ethical consumer behavior for sustainable development: the mediating role of brand attachment”, Sustainable Development, Vol. 28, pp. 1620-1631. 
$\mathrm{BFJ}$

123,13

104

Roheim, C.A., Asche, F. and Santos, J.I. (2011), "The elusive price premium for ecolabelled products: evidence from seafood in the UK market", Journal of Agricultural Economics, Vol. 62 No. 3, pp. 655-668, doi: 10.1111/j.1477-9552.2011.00299.x.

Sánchez-González, I., Gil-Saura, I. and Ruiz-Molina, M.E. (2020), "Ethically minded consumer behavior, retailers' commitment to sustainable development, and store equity in hypermarkets", Sustainability (Switzerland), Vol. 12 No. 19, pp. 1-17.

Salladarré, F., Guillotreau, P., Perraudeau, Y. and Monfort, M.C. (2010), "The demand for seafood ecolabels in France", Journal of Agricultural and Food Industrial Organization, Vol. 8 No. 1, doi: 10. 2202/1542-0485.1308.

Sanjuan-Lopez, A.I. and Resano-Ezcaray, H. (2020), "Labels for a local food speciality product: the case of saffron", Journal of Agricultural Economics, Vol. 71 No. 3, pp. 778-797, doi: 10.1111/14779552.12376.

Santagata, W. and Signorello, G. (2000), "Contingent valuation of a cultural public good and policy design: the case of 'Napoli Musei Aperti", Journal of Cultural Economics, Vol. 24 No. 3, pp. 181-204, doi: 10.1023/A:1007642231963.

Song, L., Lim, Y., Chang, P., Guo, Y., Zhang, M., Wang, X., Yu, X., Lehto, M.R. and Cai, H. (2019), "Ecolabel's role in informing sustainable consumption: a naturalistic decision making study using eye tracking glasses", Journal of Cleaner Production, Elsevier, Vol. 218, pp. 685-695, doi: 10.1016/j.jclepro.2019.01.283.

Sudbury-Riley, L. and Kohlbacher, F. (2016), "Ethically minded consumer behavior: scale review, development, and validation", Journal of Business Research, The Authors, Vol. 69 No. 8, pp. 2697-2710, doi: 10.1016/j.jbusres.2015.11.005.

Thøgersen, J., Haugaard, P. and Olesen, A. (2010), "Consumer responses to ecolabels", European Journal of Marketing, Vol. 44 No. 11, pp. 1787-1810, doi: 10.1108/03090561011079882.

Tsang, E.W.K. and Kwan, K.-M. (1999), "Replication and theory development in organizational science: a critical realist perspective", The Academy of Management Review, Vol. 24 No. 4, pp. 759-780.

Ulloa, R.R. and Gil, J.M. (2008), "Valor de mercado y disposicion a pagar por la marca Ternasco de Aragon”, Revista de Estudios Agrosociales y Pesqueros, Vol. 219, pp. 39-70.

United Nations, European Commission, FAO, IMF, OECD and The Word Bank (2014), System of Environmental-Economic Accounting 2012: Central Framework, United Nations, New York, NY, available at: http://unstats.un.org/unsd/envaccounting/ae_white_cover.pdf.

Ward, M. and Kemp, S. (2019), "The probability of conceptual replication and the variability of effect size", Methods in Psychology, Elsevier, Vol. 1 August, p. 100002, doi: 10.1016/j.metip.2019. 100002.

Yangui, A., Gil, J.M. and Costa-Font, M. (2019), “Comportamiento de los consumidores españoles y los factores determinantes de su disposición a pagar por el aceite de oliva ecológico", ITEA Informacion Tecnica Economica Agraria, Vol. 115 No. 3, pp. 252-269.

Zander, K. and Feucht, Y. (2018), “Consumers' willingness to pay for sustainable seafood made in Europe", Journal of International Food and Agribusiness Marketing, Taylor and Francis, Vol. 30 No. 3, pp. 251-275, doi: 10.1080/08974438.2017.1413611.

\section{Corresponding author}

Luca Mulazzani can be contacted at: luca.mulazzani@unibo.it

For instructions on how to order reprints of this article, please visit our website:

www.emeraldgrouppublishing.com/licensing/reprints.htm

Or contact us for further details: permissions@emeraldinsight.com 